Gerd Lau - Hans Dieter Lutz

\title{
AUTOMATIC ANALYSIS OF THE GERMAN NOUN GROUP AND SOME PROBLEMS
}

\section{0 . Introduction.}

Since 1971 the research group "Maschinelle Syntaxanalyse" (MasA) has been working as a part of the project "Linguistische Datenverarbeitung" (LDV) at the "Institut für deutsche Sprache", supported by the "Bundesminister für Forschung und Technologie" of the Federal Republic of Germany.

The task of the MasA is to elaborate a system for analysing simple sentences of present-day-German. "Simple sentences", in this case, means any type of sentence with only one finite verb in it.

\section{The scope of the analysis.}

The team works on the basis of a so-called verb grammar. In this type of grammar the verb represents the nucleus of a sentence, thus being opposed to the subject-predicate-grammar. Proposals for the elaboration of such a grammar have been presented by Helbig-Schenkel, Heringer $^{2}$ and Engel. ${ }^{3}$

This type of grammar is based on a verb lexicon, which describes all the obligatory and facultative objects that depend on the verb, e.g.

treffen with two obligatory objects in Ich treffe ihn morgen

1 G. HeLiig, Der Begriff der Valenz als Mittel der strukturellen Sprachbeschreibung und des Fremdspracherunterrichts, in "Deutsch als Fremdsprache", I (1965), pp. 10-23.

a H. J. Heringer, Theorie der deutschen Syntax, München 1970.

- U. ENGEL, Bemerkungen zur Dependenzgrammatik, in "Neue Grammatiktheorien und ihre Anwendung auf das heutige Deutsch. Sprache der Gegenwart ", XX (1971), pp. 111-155. 
treffen with one obligatory object and one facultative object in Er trifft (den Ball)

treffen auf with two obligatory objects in

Die Mannschaft traf auf einen schwachen Gegner.

After having detected the number of both the obligatory and facultative objects and specified these objects according to their syntactical functions, one can group the verbs into classes, e.g. the class of all the verbs with one obligatory object (this class contains for example the verb laufen), the class of all the verbs with two obligatory objects (containing for example treffen), the class of all the verbs with three obligatory objects (containing for example anbieten), the class of all the verbs with one obligatory and one facultative object (containing for example treffen), and so on. Each of these classes represents a so-called "Satzbauplan" (SBP).4

The systematic levels of the grammar are

a) the word class-level (WK-level)

b) the group-level (noun group (NG), verbal group (VG))

c) the complex-level (noun complex $(N K)$, verb complex $(V X)$ )

d) the object-level (nominative object $\left(\mathrm{O}_{\varrho}\right)$, genitive object $\left.\left(\mathrm{O}_{2}\right), \ldots\right)$.

The following graph can be regarded as an illustration of these four systematic levels: ${ }^{5}$

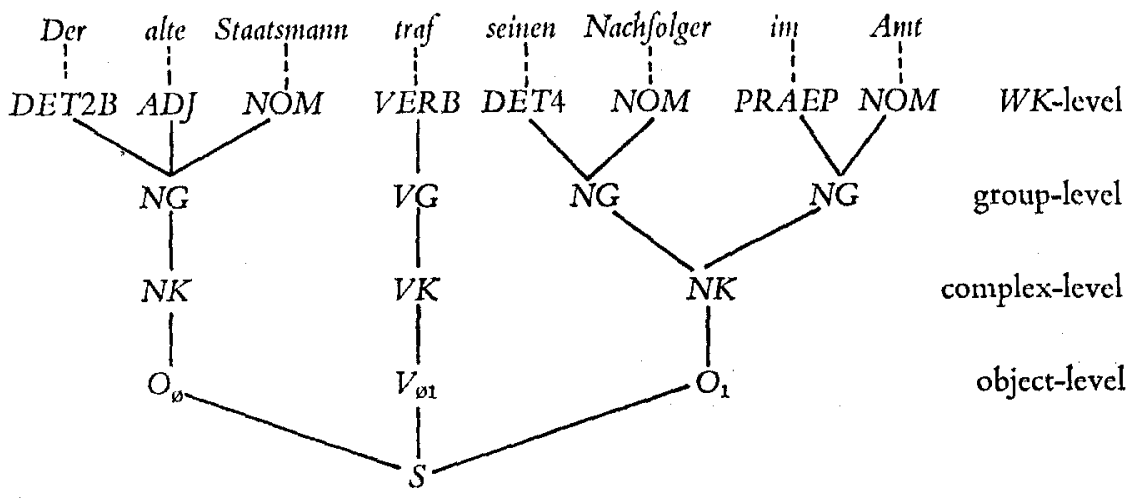

4U. ENGEL, Die deutschen Satzbaupläne, in "Wirkendes Wort", XX (1970), pp. 361392.

'For the explanation of the word classes, especially $D E T 2 B, A D J, N O M, D E T 4$, and $P R A E P$ see section $2 ; O_{\emptyset}$ stands for " nominative object", $O_{1}$ for "accusative 
The way of finding the word class of a given word form, i.e. the morpho-syntactical description of a word form, is delineated in the contribution of Werner Brecht. ${ }^{6}$

\section{Description of NG-relevant word classes.}

The following word classes are relevant for the constitution of a $N G$ :
a) preposition (postposition) PRAEP, e.g. vor
b) determinantia DET, e.g. allen
c) adverbs
$A D V, \quad$ e.g. sehr
d) non-inflected adjectives
$A D J U$, e.g. gut
e) inflected adjectives
$A D J$,
e.g. sichtbaren
f) nouns
NOM, c.g. Objekten
g) pronouns
PRON, c.g. uns.

The word classes are defined by the following morphological and/or syntactical properties:

Prepositions are collected in a catalogue and specified by their position (in front of, behind, in front of or behind, in front of and behind the nucleus of a NG), by their government (accusative, genetive, dative) and by the sort of object that is introduced by the preposition (prepositional object, situative object, directional object).

Adverbs are listed, and the list only includes words that meet the following conditions: non-inflexional; no predicative use; ccrtain regularities of position.

Non-inflected adjectives are not listed; they are described by an algorithm, which is to find out the degree of comparison.

Inflected adjectives are not listed, either. They, too, are described

object "; $V_{\emptyset_{1}}$ stands for the verb class with the "Satzbauplan" $\emptyset 1$ (obligatory nominative object plus obligatory accusative object). Note: The example is ambiguous, and only one interpretation is given. The example is ambiguous because of the noun group im Amt. This noun group may be an attribute to the noun group seinen Nachfolger. It may also be a noun group without any relation to seinen Nachfolger, and therefore it must be interpreted as a separate noun complex, which does not depend on treffen as a representation of the verb class $V_{\varnothing_{1}}$. In this case the sequence im $A m t$ is regarded as a so-called "Angabe" (cf. U. EnGBr, Linguistische Studien I Regeln zur "Satzgliedfolge". Zur Stellung der Elemente im einfachen Verbalsatz, in "Sprache der Gegenwart», XIX (1972), pp. 17-75, esp. 24ff).

B In the first Volume of this book, pp. 9-21. 
by an algorithm with respect to case, number, gender, degree of comparison and kind of inflexion (strong, weak).

Nouns are not listed in the present state of our work. There exists an algorithm that provides the description of those words according to case, number, and gender.?

In general, the definition of the several word classes is the common one, as found in the traditional grammars. But there are two exceptions: the so-called determinantia and the pronouns.

The so-called determinantia are listed in a catalogue; they are grouped with respect to the possible arrangements of several determinantia within a $N G$, e.g.

\section{vor allen diesen meinen schönen Büchern. ${ }^{8}$}

The results of having found out certain regularities are both a number of distinct subclasses of determinantia and the formulation of contextsensitive rules for analysing arrangements of determinantia.

First, there are 10 subclasses, namely

$D E T 1 A$ containing all, all-;

$D E T 1 B$ containing manch, solch, welch;

DET1C containing irgend, irgendwelch;

$D E T 2 A$ containing dies-, jen-;

$D E T 2 B$ containing $d-$, $d$-jenig;

$D E T 2 C$ containing ein-;

$D E T 2 D$ containing kein-, welch-, irgendein-, irgendwelch-, ebend-, ebend-selb-, ebendies-, $d$-selb;

DET3 containing jed-, jeglich-, jedwed;

DET4 containing mein-, dein-, sein-, uns $(e) r-$, eu $(e) r-$, ihr-;

DET5 containing einig-, etlich-, manch-, mehrer-, ein paar. ${ }^{9}$

Secondly, there are 5 rules for describing the regularities of determinantia arrangements within a $N G$ having a noun as nucleus. For

7 In future it will be possible to incorporate a more effective algorithm which reverts to an almost complete lexicon of German nouns. This lexicon has been placed at our disposal by the research group for "Automatische Lemmatisierung " at the University of Saarbrücken, W-Germany.

8 The subclassification of the determinantia is a modification of the one given in ENGEL, Regeln zur Worstellung, in « Forschungsberichte des Instituts für deutsche Sprache, Mannheim », V (1969), pp. 9-148, esp. 102ff.

${ }^{9}$ The catalogue contains all word forms of the listed stems (indicated by " - "). 
the demonstration of these rules we will use a simplified NG-structure with an abbreviated notation.

$$
\begin{array}{ll}
\text { R1: } & (D E T 1 A)(D E T 2 A)(D E T 4)(A D J) N O M \rightarrow N G \\
\text { R2: } & (D E T 1 A)(D E T 2 B)(A D J) N O M \rightarrow N G \\
\text { R3: } & (D E T 1 B)(D E T 2 C)(A D J) N O M \rightarrow N G \\
\text { R4: } & (D E T 1 C) /(D E T 2 D) /(D E T 5)(A D J) N O M \rightarrow N G \\
\text { R5: } & (D E T 2 C)(D E T 3)(A D J) N O M \rightarrow N G{ }^{10}
\end{array}
$$

It is important that there can be no iteration of a subclass of determinantia.

The rules mentioned above can be illustrated by the diagram on the next page

The pronouns are considered as pro-forms of a $N G$ with a nominal nucleus. A part of the pronouns can be grouped in several subclasses according to three significant features: possibility of using a preposition in front of the pronoun, possibility of putting determinantia in front of the pronoun, possibility of using a genitive or prepositional attribute in the post-nuclear field.

There are 9 subclasses, namely

PRON1 containing man;

PRON2 containing $d u$, er, es, ich, ihr, sie, wir;

PRON3 containing dein(er), dich, dir, einander, euch, euer, ihr(er), ihm, ihn(en), mein(er), mich, mir, sein(er), sich, sie, uns $(e r)$;

PRON4 containing all-, ebend-, ebend-selb, ebendies-, einig-, ein paar, etlich-, etwas, irgendein-, irgendetwas, irgendw-, irgendwelch-, jedermann-, jemand-, kein-, manch-, mehrer-, niemand-, nichts, w-, welch-;

PRON5A containing $d-, d$-selb-, d-jenig-, dies-, jen-;

PRON5B containing ein-;

PRON5C containing jed-, jedwed-, jeglich-;

PRON5D containing dein-, eu(e)r-, ihr-, mein-, sein-, uns $(e) r-$;

PRON6 containing selber, selbst.

\footnotetext{
10 The brackets stand for "facultative "; the slash stands for "exclusive or". A full description of the structure of a noun group with a nominal nucleus will be given in section 5.
} 


\begin{tabular}{|c|c|c|c|c|c|c|c|c|}
\hline 完 & 華 & 華 & 㺃 & 苋 & 苋 & 离 & 趉 & $\overbrace{Z}^{\beth}$ \\
\hline $\bar{\nabla}$ & 部 & 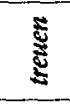 & Е & हू & 气 & छٌ & 总 & จे \\
\hline 照 & & & & & & 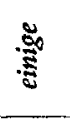 & & 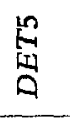 \\
\hline 曽 & & 电 & & & & & & 芯 \\
\hline 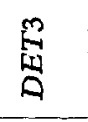 & & & & & & & $\stackrel{ \pm}{ \pm}$ & 蜔 \\
\hline 兽 & & & & & 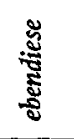 & & & 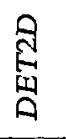 \\
\hline 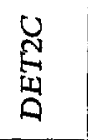 & & & : & & & & 플 & 荡 \\
\hline 莕 & & ॠँ & & & & & & 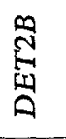 \\
\hline$\underset{\mathbb{H}}{\mathbb{H}}$ & : ّ. & & & & & & & 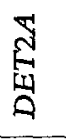 \\
\hline 芯 & & & & 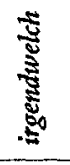 & & & & 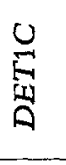 \\
\hline 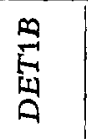 & & & 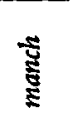 & & & & & 甍 \\
\hline 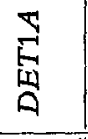 & ปั & $\bar{\nabla}$ & & & & & & 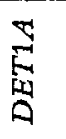 \\
\hline$/$ & $\ddot{\ddot{q}}$ & $\ddot{\mathscr{Z}}$ & $\ddot{\ddot{2}}$ & 華 & & & $\ddot{\ddot{Q}}$ & 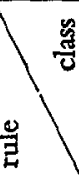 \\
\hline
\end{tabular}


But, there is another group of pronouns without the characteristics mentioned above, i.e. without pre-nuclear field, without a preposition in front of them, without post-nuclear field. These pronouns do not differ at the NG- or NK-level. But they differ at the O-level, when you try to detect if such a pronoun is a substitute for an object (depending on the verb) or a substitute for a so-called "Angabe" (which does not depend on a verb). .1 Furthermore, pronouns that can be substitutes for an object, can be differentiated according to the kind of these objects.

So, there are six more subclasses, namely

PRON7A containing wobei, wofïr, womit, wonach, woraus, worum, wovon;

PRON7B containing wo, wohinter, woneben;

PRON7C containing woher, woherauf, woheraus, woherein, woherüber, wohin, wohinaus, wohinein, wohiniber;

PRON7D containing woran, worauf, worin, woriber, worunter;

PRON7E containing wogegen;

PRON8 containing inwiefern, inwieweit, wann, warum, weshalb, weswegen, wie, wieso, wodurch.

Pronouns of $P R O N 7 A$ are substitutes for prepositional objects $\left(\mathrm{O}_{4}\right)$; pronouns of $P R O N 7 B$ are substitutes for situative objects $\left(O_{5}\right)$; pronouns of PRON7C are substitutes for directional objects $\left(O_{6}\right)$; pronouns of $P R O N 7 D$ are substitutes for $O_{4}$ or $O_{5}$; pronouns of PRON7E are substitutes for $\mathrm{O}_{4}$ or $\mathrm{O}_{6}$; pronouns of PRON8 are substitutes for socalled "Angaben".

The final division of pronouns in 15 subclasses makes it possible to set up rules for detecting and describing NGs with a pronominal nucleus. For the demonstration of these rules we will use a simplified and abbreviated notation.

R6: PRON1 / PRON2 $\rightarrow N G_{ø}$

R7: $\quad P R O N 6 \rightarrow N G_{3} \rightarrow N G_{\text {Attr. }}$.

R8: (PRAEP) $\{$ PRON3 / PRON4 $\} \rightarrow N G_{\text {? }}$

R9: (PRAEP) $\{\{(D E T 1 A)$ PRON5A $\} /\{(D E T 1 B)$ PRON5B $\}$

| $\{(D E T 1 C)$ PRON5C $\} /\{(D E T 1 A)(D E T 2 A \mid$

$D E T 2 B) P R O N 5 D\}\} \rightarrow N G_{?}$

\footnotetext{
11 The reason for these pronouns not being included in PRON1 (which meets the same conditions at the first glance) is that man of $P R O N 1$ covers always the position of a nominative object $\left(0_{\emptyset}\right)$, in contrast to the pronouns of PRON7A to PRON8.
} 


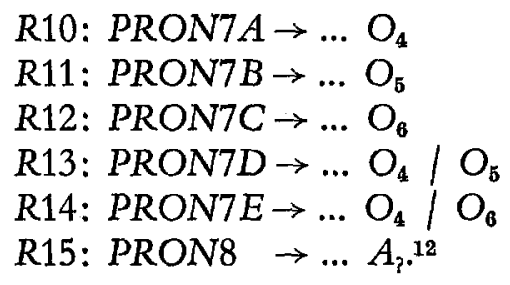

This collection of rules shows the difference between PRON1 ... PRON6 and PRON7A ... PRON8. A comparison with the rules $R 1$ to $R 5$ illustrates that there are less possibilities to combine determinantia in front of the nucleus of a pronominal NG. Other differences will be discussed in section 3 .

\section{Two types of NGs.}

It is no new observation that there are at least two different types of NGs in German.

The first type covers all NGs having a noun as nucleus of the NG, e.g. die Mitbestimmung,

the second type covers all NGs with a pronoun as nucleus of the $N G$, e.g. sie, die unsere, woran.

The structure of the NG depends on what kind of nucleus appears.

In a $N G$ with a pronominal nucleus, there can be no adverbs, no non-inflected adjectives, and no adjective - in opposition to a NG with a noun as a nucleus.

In a pronominal NG there are less possibilities of arranging determinantia than in a nominal NG (see rules $R 1-R 15$ ). The reason is quite evident: by suppressing the noun (nucleus) in a nominal $N G$, the last determinans turns into a pronoun, i.e. it represents the nucleus in a pronominal NG. Compare the following two examples:

alle diese Bücher DET1A DET2A NOM<smiles>[14CH3]C[14CH3]</smiles>

vs. alle diese DET1 $A$ PRON5A nucleus

12 The "?" indicates that the case of the NG is not predictable in general. " A" is an abbreviation of "Angabe". The braces are to denote larger units belonging to each other. For the explanation of other signs see footnote 10 . 
There is another difference beween a nominal $N G$ and a pronominal one: in nominal $N G s$ one can find other NGs embedded:

die Ansprachen haltenden Parlamentarier, or (rather complex)

die nach Marx alle menschlichen Handlungen wesentlich

und zu aller Zeit zum Nachteil der Mehrheit der Bevölkerung bestimmenden Kapitalgesetze.

In both cases the first die belongs to the last word, to Parlamentarier and Kapitalgesetze; die Parlamentarier and die Kapitalgesetze form the hierarchically highest $N G$. If you transform the determinans of this highest NG into a pronoun such as sie, there is no possibility of embedding other NGs in this pronominal $N G$. This explains the difference between a nominal NG and a pronominal one, too.

\section{Criteria for the analysis.}

The different elements of a German NG underlie different kinds of syntagmatic relations. The number of these relations varies corresponding to the two types of NGs.

Four kinds of relations are relevant for the nominal NG:

congruity between adjectives and nouns (concerning case, number, and gender)

between determinantia and nouns (concerning case, number, and gender)

between prepositions and nouns (concerning the case of a noun and the possible government of a preposition)

between determinantia and adjectives (concerning case, number, and gender);

inflectional relation between determinantia and adjectives (concerning the inflexion of a determinans and the inflexion of a following adjective;

degree of comparison of the adjective of the nominal NG (providing the connection with further parts of the syntactical analysis);

compatibility of subclasses of determinantia according to the rules $R 1$ to $R 5$; the rule of compatibility of nominal $N G$ has the form: 


$$
\begin{array}{r}
((\text { det }=1) \Rightarrow((M(W K, I, n-i)=D E T 1 A \vee(M(W K, I, n-i+1)= \\
=D E T 2 A \vee D E T 2 B \vee D E T 4)) \vee \\
\vee((M(W K, I, n-i)=D E T 2 A \wedge(M(W K, I, n-i+1)= \\
=D E T 4))) \vee
\end{array}
$$

Only two kinds of relations are relevant for the pronominal NG: congruity between determinantia and pronouns (concerning case, number, and gender)

between prepositions and pronouns (concerning the case of a pronoun and the possible government of a preposition);

compatibility of subclasses of determinantia according to the rules $R 6$ to $R 9$; the rule of compatibility of a pronominal NG has the form:

$$
\begin{aligned}
((\operatorname{det}=1) \Rightarrow((M(W K, \quad I, \quad n-i)=D E T 1 A) \wedge & (M(W K, \quad I, n-i+1)= \\
& =D E T 2 A \vee D E T 2 B))) .
\end{aligned}
$$

Summing up, there are only two kinds of relations of the pronominal $N G$, but four kinds of relations of the nominal $N G$; the set of the various congruity relations noticeable at the nominal $N G$ differs from the one noticeable at the pronominal $N G$; and the compatibility

\footnotetext{
${ }^{13}$ This notation is a conglomerate of matrix-notation, logical signs, and of programmer's conventions. It can be read: "If the value of the counter "det" equals 1 , then the value of the place " $W K$ " of the matrix " $M$ " at the level " $I$ " at the position " $n-i$ " must have been "DET1 $A$ " and the value of the place " $W K$ " of the matrix " $M$ " at the level " $I$ " at the position " $n-+1$ " must have been DET $2 A$ or DET2B or DET4, or the value of ..." and so on.

$M$ is a three-dimensional matrix which gets built up during the morphological analysis of an input sentence, and which contains all computed information of all the words of this sentence. " $I$ " stands for "interpretation" and is a variable, running from 1 to 50. At the moment, " $W K$ " stands for "word class" with 40 different specifications. " $n$ " indicates the position of the noun in a given sentence, and " $i$ " is a position counter; so, if $n=3$ and $i=1$, then $n-i=2$, i.e. the position in question is the next to the noun on the left side.
} 
rule for the nominal NG si much more complex than that for the pronominal $N G$.

\section{An algorithm as representation of a hyperrule.}

The preceding outlines displayed the complexity of contextual restrictions concerning German noun groups. It sounds extremely clumsy to talk about these restrictions in a natural language. We therefore developed a formal notation for the communication between linguists and programmers of our team. It consists of a matrix-notation, sentential connectives, functions and flow chart conventions. The compatibility rules were a small cut-out. For more details see our forthcoming publication. ${ }^{14}$

In the following, we will discuss the nominal NG only, because its structure and its difficulties are more interesting than the structure of the pronominal NG.

At the present state of our algorithm the following constructions have been excluded: coordination of adjectives, fusion of prepositions and certain determinantia (i.e. am being $a n+d e m$ ), postponed prepositions, prepositions like um ... willen, and embedded participle constructions.

The reason for excluding embedded participle constructions is that, in our opinion, complex constructions like these can be analyzed after the successful interpretation of simple sentences only. The other restrictions montioned above are not so important, i.e. the solution of these problems are, more or less, not so difficult, and, in fact, one of our collegues has made a proposal for the treatment of all kinds of prepositions.

At the moment, we will consider the following hyperrule and we will interprete it as a statement about the word order only:

$$
\begin{gathered}
(P R A E P) \quad(D E T)(D E T)(D E T) \quad\left(\left(\left(A D V^{\star}\right) A D J U^{\star}\right)\right. \\
A D J)^{\star} N O M \rightarrow N G . .^{15}
\end{gathered}
$$

${ }_{14}$ Arbeitsgruppe MASA, Zur maschinellen Syntaxanalyse I: Morphosyntaktische Voraussetzungen für eine maschinelle Sprachanalyse des Deutschen, in "Forschungsberichte des Instituts für deutsche Sprache, Mannheim ", XVIII, 1, XVIII, 2, 1974.

16 The asterisk indicates the possibility of iterating. For the explanation of the other signs see footnote 10 . 
The program that is intended to analyze nominal NGs first looks for a $N O M$, proceeding from the left to the right. After having found a NOM, the whole algorithm will be called up in order to search an $A D J$ to the left of the NOM. $A D V^{\star}$ and $A D J U^{\star}$ can appear only in case an $A D J$ has been found. Otherwise the algorithm turns to $D E T$, which tests the word order and compatibility of the DETs if there exists a DET. There are no more than three DETs admitted. PRAEP is the word class which stands at the extreme left in German NGs (according to our restrictions); it is the last one to be looked for.

In many cases the output of this analysis depends on homography. An example may prove this as well as the fact that there remain lots of ambiguities at this level of analysis:

(2) nahe so sehr gründlich vergifteten Wäldern

IPRAEP ADV ADV ADJU ADJ NOM। description 1

$V E R B, A D V A D V \quad A D J U \quad A D J \quad N O M_{\mid}$description 2

VERB $A D V_{\mid} A D V$ ADJU ADJ $N O M_{\mid}$description 3

VERB ADV ADV $A D J U$ ADJ NOM $M_{\mid}$description 4

$V E R B \quad A D V A D V A D J U, A D J \quad N O M_{\mid}$description 5

VERB ADVADV ADJU VERB ${ }_{\text {NOM }}$ description 6

(3) vor so sehr grïndlich vergifteten Wäldern

IPRAEP ADV ADV ADJU ADJ NOM

If $P R A E P$ is a homograph, $A D V^{\star}$ and $A D J U^{\star}$ may or may not be constituents of the nominal NG (see (2)). If PRAEP is no homograph and if there is no DET, the whole string must be a $N G$ (see (3)).

As homographs may exist, the algorithm is constructed in the following way: in a first step the longest nominal NG possible is built up, and in a second step this nominal $N G$ is minimized in all possible interpretations (in the case of (2) there are five interpretations which cover shorter nominal NGs than the first one). 
6. Problems concerning the identification of a "nominal complex" (consisting of a NG or of a number of NGs).

A nominal complex $N K$ is a noun group or a string of noun groups which are part of a sentence. Yet, this gives no information about the role the $N K$ plays in the sentence: a $N K$ can be either an object which depends on the finite verb, or an "Angabe". NKs in the nominative case can serve as objects only, i.c. as subjects of sentences. The following schedule displays that any $N K$ with an $O$-value between 1 and 6 can be either an object or an "Angabe":

\begin{tabular}{lcc} 
O & Object & "Angabe" \\
\hline 1 & Er wiegt zwei Kilo & Er läuft zwe i Meter \\
\hline 2 & Er gedenkt des Morgens & Er läuft des Morgens \\
\hline 3 & Er gibt mir Wein & $\begin{array}{l}\text { Er steigt mir auf den Fuß } \\
\text { Er trägt mir den Koffer }\end{array}$ \\
\hline
\end{tabular}

4 Er rechnet mit dem Vor- Er verdient mit dem Vortrag des Bruders trag des Bruders

$5 \quad$ Er wohnt im ersten Stock Er schläf im ersten Stock

6 Ergeht ins Kino hinein Er schläft in den Tag hinein

Thus we cannot derive any knowledge about a NK's function from its grammatical description only. But semantical criteria can provide some solutions at this level of analysis:

Er rechnet mit dem Vortrag seines Bruders.

(4) contains the verb rechnen mit +1 with the "Satzbauplan" $S B P$ $\emptyset 4$. But (4) contains also the verb rechnen with $S B P \emptyset$. As the semantic features of Vortrag tell us that Vortrag is no means of calculating, the $S B P \varnothing$ will be excluded as an incorrect derivation. 
(5) contains the same verbs as (4). As Rechenmaschine is a means of calculating, the $N K$ is also an "Angabe". Therefore both $S B P \emptyset$ and $S B P \emptyset 4$ are possible analyses.

But we do not yet follow semantics. We try to analyze with syntactic means as long as possible.

If we combine two NGs in order to build a $N K$, the right $N G$ serves as an attribute:

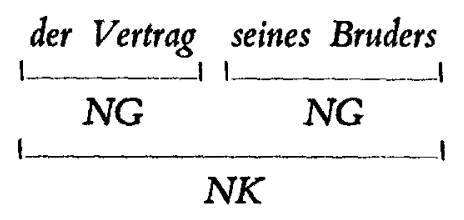

An attribute is a $N G$ with one of the following O-values:

$$
\begin{aligned}
& O=2 \text {.... genitive phrase: der Vortrag seines Bruders } \\
& O=4 \text {.... prepositional phrase: der Mann mit dem Kropf } \\
& O=5 \text {.... situative phrase: der Baum im Garten } \\
& O=6 \text {.... directional phrase: die Fahrt in die Stadt }
\end{aligned}
$$

The rules $R R 1$ and $R R 2$ define an algorithm which is to build $N K s$ of NG-combinations. Further on, $R R 3$ and $R R 5$ change a NK into an object, and RR4 an NK into an "Angabe".

$$
\begin{aligned}
& L_{i} \ldots \text { leftmost position of a } N G_{i} \text { or a } N K_{j} \\
& R_{i} \ldots \text { rightmost position of a } N G_{i} \text { or a } N K_{j} \\
& O_{i} \ldots \text { value of the "object class" of a } N G_{i} \text { or } N K_{j} .
\end{aligned}
$$

RR1: $\quad N G_{i}\left(L_{i}, R_{i}, O_{i}\right)=N K_{j}\left(L_{i}, R_{i}, O_{i}\right)$

RR2: $\quad N G_{i}\left(L_{i}, R_{i}, O_{i}\right)+N K_{j}\left(L_{j}, R_{j}, O_{j}\right)=N K_{k}\left(L_{i}, R_{j}, O_{i}\right)$ on condition that 1) $R_{i}+1=L_{j}$;

2) $O_{j}=$ either 2 or 4 or 5 or 6 ;

3) $N G_{i}$ does not contain a preposition behind the noun.
RR3: $\quad N K_{j}\left(L_{j}, R_{j}, O_{j}\right)=O_{j}\left(L_{j}, R_{j}, O_{j}\right)$ (i.e. a derivation of on condition that $O_{j} \neq \varnothing . \quad$ an object.)


RR4: $\quad N K_{j}\left(L_{j}, R_{j}, O_{j}\right)=A_{j}\left(L_{j}, R_{j}, O_{j}\right)$ (i.e. a derivation of on condition that $O_{j} \neq \varnothing$. an "Angabe".) RR5: $\quad N K_{j}\left(L_{j}, R_{j}, \varnothing\right)=O_{j}\left(L_{j}, R_{j}, \varnothing\right) \quad \begin{aligned} & \text { (i.e. the derivation of } \\ & \text { the subject.) }\end{aligned}$

Consider an example of a possible application of $R R 1-R R 5$ in order to combine three $N G$ and thus make a single $N K$ :

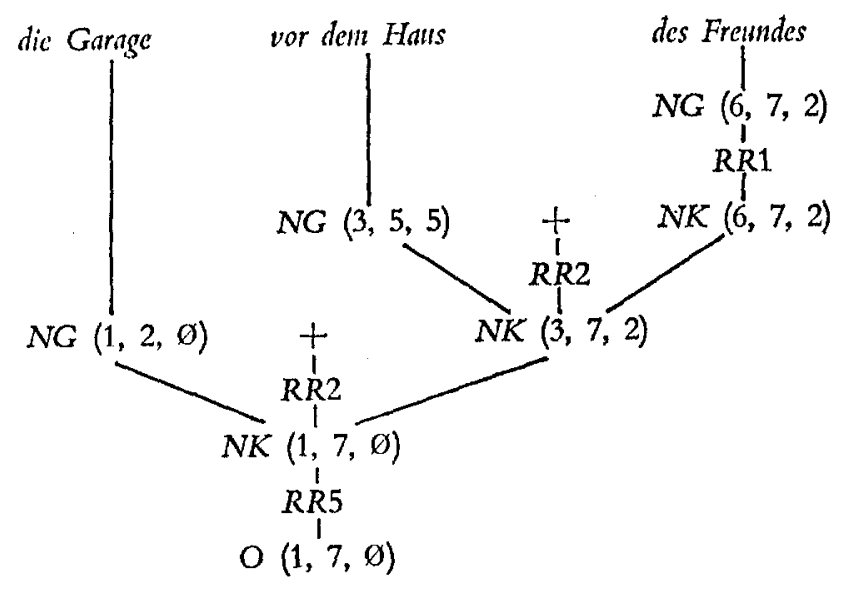

Exceptional case I: Prepositions in front of, and behind, a NG or NK.

$$
\begin{aligned}
& \text { um des Freundes willen } \\
& \text { um des Freundes in Paris willen }
\end{aligned}
$$

Evidently (7) is no string of two NGs. Therefore, $R R 1$ and $R R 2$ are not applicable to this type of $N K$, and we must construct a special algorithm for the analysis of it.

Exceptional caseII: Preposition behind a NG or a NK.

In German there are some prepositions which can appear in front of, or behind, a NG, for instance nach, wegen, ...

Er zittert wegen des Kampfes or Er zittert des Kampfes wegen.

When we consider (8), (9) and (10) we see that a postposition in a $N G$ at the same time is a postposition of a $N K$. 
(8) des Kampfes wegen

(9) des Kampfes in der Sporthalle wegen

(10) des Kampfes in der Sporthalle in Bonn wegen

We need a special algorithm for the analysis of NKs of the type (8)(10). It must provide, for instance, the following analyses of (11):

(11) Er entsinnt sich des Beifalls wegen des Gesanges.

$$
\begin{array}{lll}
\text { analysis a) } \ldots . N G(4,5,2) & N G(6,8,4) \\
\text { analysis } b) \ldots N G(4,6,4) & N G(7,8,2)
\end{array}
$$

It is possible to unite both NGs of a) into one $N K$ by application of $R R 1$ and $R R 2$. But in $b$ ) this is impossible; condition 3. of $R R 2$ is not met. Therefore both NGs in b) must be changed into separate $N K s$ by $R R 1$.

Another quite complicated example:

(12) Er entledigt sich des Freundes des Boxens wegen des Messers

$$
\text { analysis a) ... } \frac{N G(4,5,2) N G(6,7,2) N G(8,10,4)}{N K(6,10,2)}
$$

(12) Er entledigt sich des Freundes des Boxens wegen des Messers

$$
\text { analysis } b) \ldots \frac{N G(4,5,2) \quad N G(6,8,4)}{N G(9,10,2)}
$$

$R R 1-R R 5$ and the special algorithms for exceptional case I and II are the theoretical basis to find all possible combinations of NGs and to derive objects and "Angaben" from NKs.

Next we check the syntax for useful hints so as to achieve a correct analysis of NKs of a given sentence, and hints so as to decide, which NKs are objects and which are "Angaben". 
In (13) and (14) we find NGs of the same structure. But the correct analysis of (13) differs completely from that of (14).

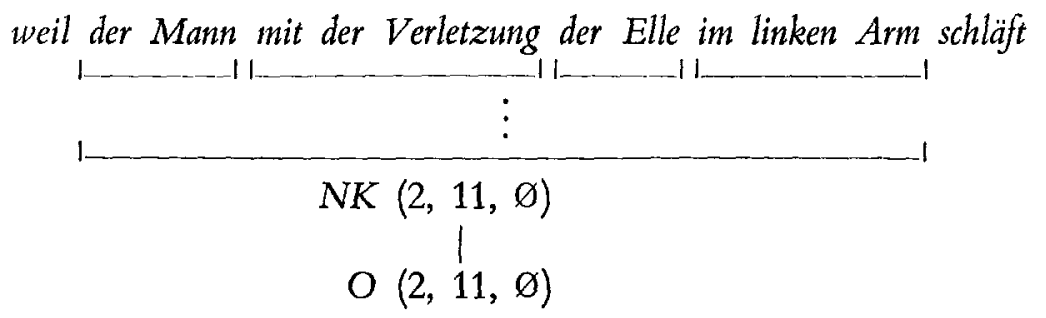

(14)

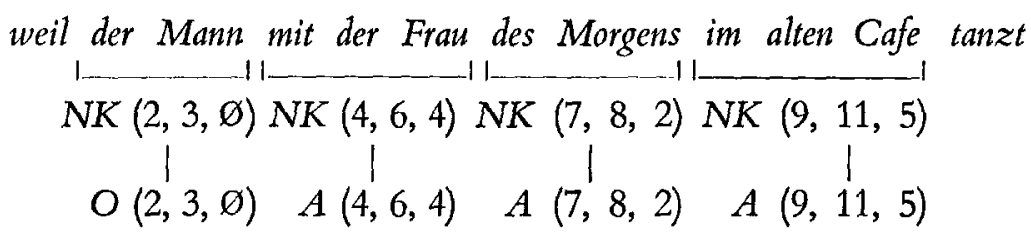

As long as we do not find any hints, the rules must be applied in a systematic order, so as to have all possible analyses as a result. A semantic component then can choose the subset of reasonable analyses out of the whole set. Thus the analysis of (13) would have to be an analysis of (14), and vice versa.

It would need too much space to print the set of theoretically possible analyses of (15) here. The reader easily sees, in how many different ways $R R 1-R R 5$ can be applied. The whole set of possible analyses is greater than 100 ! We just show a single analysis. We note the rule being applied in the leftmost column. Now we try to use the "Satzbauplan" as a means of improving the exhaustive analysis-procedure. In (15) wartete is the single finite verb. It has the $S B P \varnothing 4$ auf +1 . That means, it takes both an object in the nominative case and a prepositional object. Having found a certain $S B P$, our algorithm runs as follows:

1. Look for a $N G(,, \varnothing)$ and make it an object. (According to $R R 1, R R 5$.)

2. Look for a $N G(,, 4)$ which contains the preposition auf, and make it an object. (According to RR1, RR3.)

3. Apply $R R 1, R R 2$ and $R R 4$ to the NGs which are not objects.

4. Try to analyze one of the NGs which are not objects as an attribute of an object. If this is possible, restart at 3.; if not, stop! 


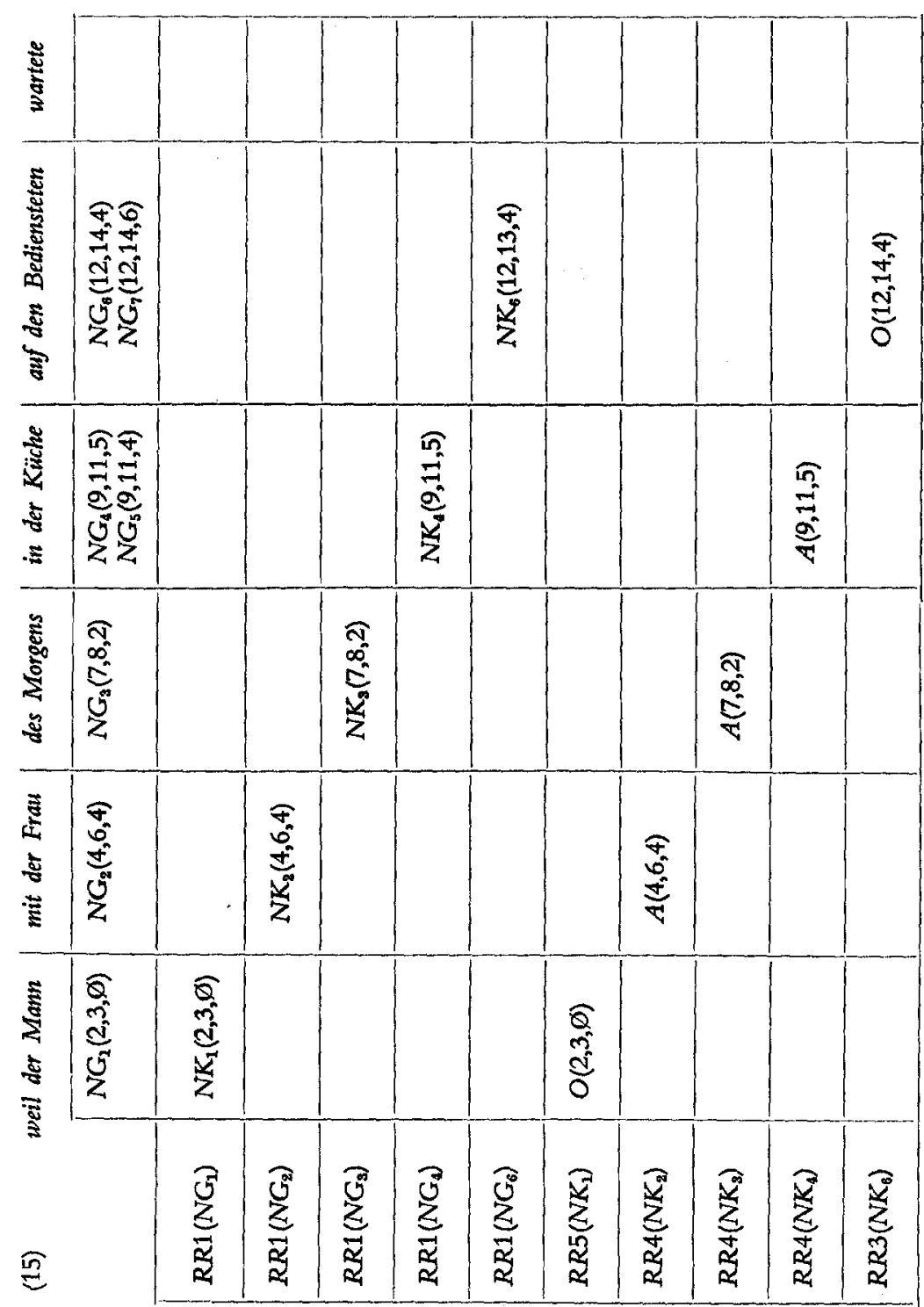




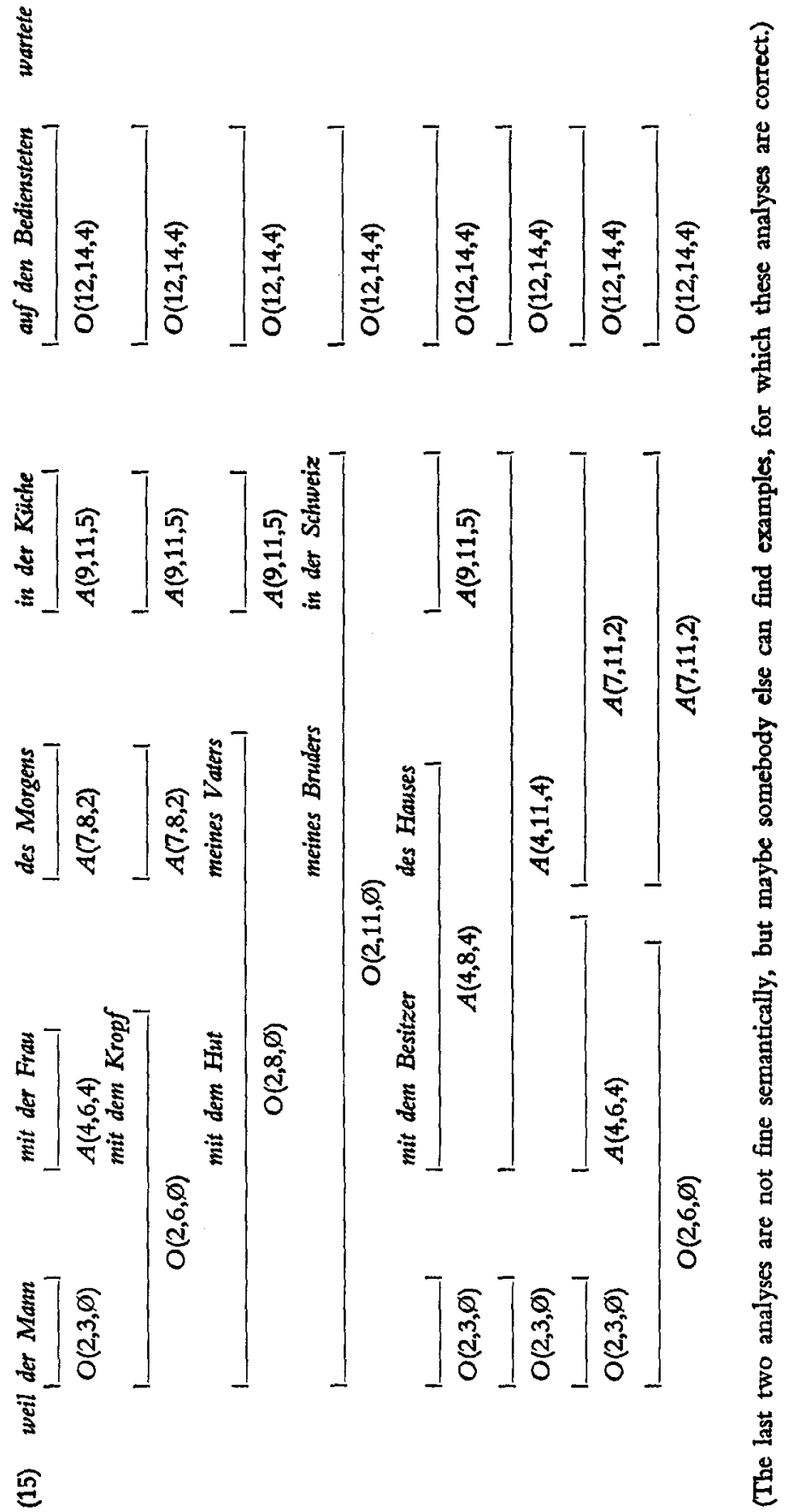


In the case of (15), this algorithm produces no more than 8 analyses. That means that the unshortenend result of more than 100 analyses can be reduced to 8 by using an improved version of analysis. This shows that the $S B P$ gives us the syntactical information which is necessary to make the correct analysis.

On the opposite page we show that all 8 analyses are possible with the SBP Ø 4 auf +1 and the structure of NGs as in (15).

Sometimes one can find more than one finite verb in a sentence:

$$
\begin{aligned}
& \text { Er liebe bestimmte nahe } \\
& \begin{array}{llll}
\operatorname{verb}_{1} & \text { verb } & \text { Wälder } \\
\operatorname{adj}_{1} & \operatorname{adj}_{2} & \operatorname{verb}_{3} \\
& & \operatorname{adj}_{3} \\
& & \text { prep }_{1} \\
& & \text { adju }
\end{array} .
\end{aligned}
$$

In these cases one has to find out which of the verbs is the actual finite verb. In German the finite verb can appear at the first position in the sentence, at the second position, and at the end. It is easy to fill up the following matrix according to the verbs in (16):

\begin{tabular}{|l|c|c|c|}
\hline \multicolumn{1}{|c|}{ verb } & $1^{\text {st }}$ position & $2^{\text {nq }}$ posizion & end \\
\hline $\begin{array}{l}\text { liebe } \\
\text { bestimmte } \\
\text { nahe }\end{array}$ & - & + & - \\
\hline
\end{tabular}

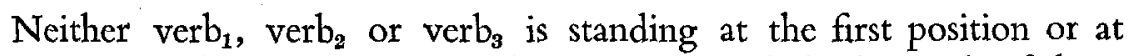
the end of the sentence. From that we can conclude that each of them must be at the second position of the sentence. We still know another criterion to find the right verb: The string in front of it, at position 1 , must be an NK. In (16) only verb $b_{1}$ meets this condition. Therefore liebe is the finite verb.

Only if one knows a lot of syntactical heuristics like these, one is able to decide at which level of sentence-analysis semantics should be employed. We think there will be need for an interaction between a syntactical and semantical component. 